\title{
The effectiveness of distance learning of financial literacy of university students in a pandemic
}

\author{
I.S. Vinnikova ${ }^{1 *}$, E.A. Kuznetsova ${ }^{2}$, and E.V. Shpilevskaya ${ }^{3}$ \\ ${ }^{1}$ Minin Nizhny Novgorod State Pedagogical University, Nizhny Novgorod, Russia \\ ${ }^{2}$ Minin Nizhny Novgorod State Pedagogical University, Nizhny Novgorod, Russia \\ ${ }^{3}$ The All-Russian State University of Justice (RLA of the Ministry of Justice of Russia), Rostov-on- \\ Don, Russia
}

\begin{abstract}
The article discusses the issue of the effectiveness of teaching financial literacy, in the aspect of the knowledge received by students of higher education following the results of the implementation of lessons in a distance format in the mode of self-isolation and pandemic. The authors have identified key indicators that make it possible to form an objective assessment reflecting the level of knowledge and skills acquired based on the results of studying the discipline, as well as draw conclusions about the possibility of implementing financial literacy training in distant mode without reducing the final indicators of learning.
\end{abstract}

\section{A problem statement}

The modern system of higher education currently sets itself the goal not only to form key competencies for the implementation of professional activities in the chosen direction, but also to prepare students for making key decisions in many areas of life. The formation of financial literacy and the provision of the opportunity to acquire the skills of competent financial planning and management during the period of higher education and for the future is in the first positions as a priority task.

Over the past five years, the government of the Russian Federation has been implementing a program to improve the financial literacy of the population, in which special attention is paid to the issue of organizing work with young people during the period of their higher education.

\subsection{The objective of the work}

The specificity of disciplines aimed at the formation of financial literacy is the objective need for a large number of practical examples and training of skills in the theoretical part of the information being studied. As a rule, it is precisely to test the ability to apply the acquired knowledge in practice that the control following the results of studying such

${ }^{*}$ Corresponding author: prof-ped.gpa@mail.ru 
disciplines is directed. This applies not only to prudent or rational consumption, but also to the formation of financial policy within the family and competent planning of the family budget. Correctly selected assessment tools allow you to objectively assess the learning process, both as a result of studying the discipline and at the stages of the implementation of intermediate control [1].

The pandemic and the transition to distance learning have made certain adjustments not only in the construction of the educational process, but also brought to the fore the issue of the effectiveness of such training in all areas of training, and also forced to revise the procedure for assessing the level of effectiveness of the classes being implemented. For this reason, there is an objective need to form an assessment that objectively reflects the effectiveness of distance learning with the aim of possible modernization of the educational process and its improvement in the new conditions.

\section{Results of the research}

In the modern realities of the development of society, financial literacy is a necessary aspect of the life of any person, since all people have to make various decisions in the field of finance and their distribution. Financial literacy is one of the most important competencies of a modern student, both in economic and non-economic areas of training. It allows you to optimally plan and apply your own budget based on short-term and long-term interests, recognize financial threats, navigate the market for services and products provided by financial institutions, and avoid debts and fraud.

If we talk about the concept of financial literacy, then it can be defined as the presence of students' knowledge, skills and abilities in the field of understanding various aspects of financial reality: the country's economy, the financial situation of the population, the characteristics of modern credit relations, the state of the market, personal finance, including number of comparing personal income and expenses. The formation of financial literacy among students is directly related to the process of understanding fundamental economic concepts and processes by them. It is expressed in the ability to accept and reflect on real economic events and, at the same time, their correlation with the knowledge gained in this area $[1,2]$.

The problem of teaching financial literacy has been studied by many domestic and foreign researchers. I would like to refer to the work of A.V. Zelentsova, E.A. Bliskavki and D.N. Demidov, who determine the development of financial literacy in students as a promising area of activity of an educational organization. The researchers note that the study of the basics of financial literacy by students has a positive effect on the level of the country's financial culture as a whole, which is one of the most important goals of the state. In foreign practice, financial literacy is considered as the ability to manage one's own personal finances and make optimal financial decisions that ensure the achievement of short-term and long-term goals [3].

Researcher Yu.A. Antonova notes that in the process of studying financial literacy by students, the most effective educational technology is the pedagogy of cooperation, which directly includes personality-oriented areas of study, which significantly increase the motivation of students to learn [4].

The authors analyzed the results of studies of the consequences of the impact of learning conditions during a pandemic on modern society. A separate emphasis was placed on the organization of the educational process and control of different categories of knowledge in general. The majority of domestic and foreign authors come to the conclusion that the use of distance learning in various areas of training is not inferior in terms of the effectiveness of the presentation of material in a traditional format. At the same time, they note that 
performance indicators are directly correlated with the level of student involvement in the educational process and responsibility in the aspect of acquiring knowledge $[5,6,7]$.

It is worth noting that the pandemic as a key factor that influenced the restructuring of the learning process and is an unforeseen factor for all areas of activity for modern society has caused a large number of discussions about the consequences and order of the effective organization of the education system in the current conditions around the world.

At the videoconference of the Special Group of Ministers of Education, held by UNESCO on 10.03.2020, various issues of large-scale measures to help teachers and students in home schooling in connection with quarantine were discussed. Key issues touched upon both the learning process itself and the assessment of learning outcomes. Based on the results of the conference, they formulated recommendations for organizing the learning process in a distance format for the period of a pandemic.

The main result of the presented research is the analysis of the results of constructing teaching financial literacy of university students in a distance format. To maintain effectiveness, as in the format of traditional education, the teacher is faced with the task of organizing classes in maximum contact with students and building control in a sufficient and necessary volume to achieve maximum results in the current learning conditions. The authors emphasize the importance and necessity of developing a personality-oriented approach for the maximum effectiveness of the educational process in the formation of financial literacy.

Every year, modern education more and more goes into the digital environment, allowing you to master new knowledge without being present in classrooms and visiting educational institutions. This phenomenon, quite new for the Russian education system, makes it possible to open up opportunities for acquiring knowledge for everyone who, for whatever reason, is limited in their ability to take part in the educational process in the usual format.

The conditions of the pandemic forced to reconsider traditional approaches to teaching and led to an operational restructuring of the educational process from the usual format of conducting classes to the mode of remote communication with the audience. This work procedure led to the fact that both teachers and students had to make a lot of efforts to build the educational process without losing the quality of education. In this case, special attention was paid to the disciplines included in the training base and forming the foundation of the knowledge acquired: determining the skills and abilities necessary not only in the future profession, but also in everyday life.

Classes on the formation of financial literacy within the bachelor's curriculum, as well as for other disciplines, include classes in the format of lectures, practices and independent work. All types of tasks performed in the classroom can be checked by the teacher, subject to discussion and disassembled in detail both individually and in a group format. The usual format of work allows you to build a control system for the acquired knowledge and additional training of skills, if necessary.

The distance learning system, which excludes the possibility of personal contact with the teacher and assumes a large amount of independent work, requires a different control system, since with a large amount of material studied independently, the level of motivation is much lower, which in turn affects the results of the study.

An increase in the effectiveness of training in this case can be directly related to the degree of elaboration of the individual route for studying the discipline by the student, i.e. with the possibility of applying a student-centered approach aimed at individualizing learning.

When studying financial disciplines, various personality-oriented educational technologies developed by leading teachers and practitioners can be actively used [8, 9, 10]. Let us dwell on the developing, research technologies, such is the IBM technology (Inquiry 
Based Methods) - methods based on research. Let us single out such well-known techniques as heuristic learning, PBL (Problem Based Learning) - learning based on solving problems, Project Based Learning - a method of projects, RBL (Resource Based Learning) learning based on the use of information resources.

The applications of IBM technologies are not just the use of guidelines for organizing the process of financial and economic education. The goal of IBM pedagogy within the financial disciplines is to educate a comprehensively developed personality who is able to set various financial tasks, conduct his own analytical research using appropriate tools and analysis methods, and think critically and logically. It is obvious that financial education plays a major role in the formation of such a personality.

When teaching financial disciplines, heuristic training has proven itself, activating the intellectual and creative activity of students, which allows maintaining motivation to master the necessary knowledge of the discipline. A number of accompanying factors also contribute to an increase in the efficiency of the educational process in the implementation of financial disciplines, namely:

- in the learning process, participants in the educational process are active, and the topics studied are of interest to them;

- educational financial activities differ from traditional ones and are aimed, first of all, at the creative self-realization of students;

- while acquiring research and reflection skills, students use them in other educational contexts;

- the basis for obtaining new financial skills and strategies is the previous experience of students and previously acquired knowledge and skills;

- both the independence and autonomy of students and joint work in a group at certain stages of completing financial tasks are encouraged.

In addition to the presented advantages of heuristic technologies in teaching, one should take into account some disadvantages that do not allow their use in each lesson:

- mastering the material of the topic of financial discipline often takes more time than with the direct method of teaching;

- increasing requirements for the material and technical support of the educational process;

- the effectiveness of the learning process depends on the actual level of financial literacy of students, the level of proficiency in self-education strategies;

- although the heuristic method presupposes the active involvement of students in educational and cognitive activities, they are not always able to independently identify patterns, shortcomings, formulate conclusions by analyzing financial and economic situations;

- heuristic learning requires additional training from the teacher in the creation and management of a heuristic educational environment (advantages for those teachers who have advanced training in a heuristic format);

- additional time requires the development of educational and methodological support of financial disciplines, which, given the actual workload of the teacher, is often difficult to implement.

Summarizing, we can conclude that the heuristic method is certainly a very valuable teaching method in general and in relation to financial sciences in particular, but its use should be consistent with specific educational results.

A method that has turned out to be especially in demand from a practical point of view today in higher education, and not only in teaching financial disciplines, is the PBL (Problem Based Learning) method. It is based on problem solving. His fame can be explained by the fact that the topics and problems studied are based on real life situations, 
and the educational process itself involves working in groups, conducting research, collecting, studying and analyzing information, critical thinking, etc.

The main advantages of the PBL method include the following:

- the possibility of forming independent educational trajectories for students;

- the formation and development of students' skills of critical and analytical thinking;

- formation of the ability to find and use the necessary sources of information;

- growth of students' motivation by studying relevant and interesting topics of the discipline and solving real situational financial problems;

- use in the classroom knowledge and skills acquired in the study of other core or noncore disciplines, etc.

In addition, a number of problems can be identified when using the PBL method in financial disciplines:

- the difficulties that students overcome in the selection of the necessary financial information;

- the lack of flexibility of thinking among a number of students and, consequently, consideration of the presented financial problem in a narrow perspective;

- the level of complexity of some of the financial and economic problems under consideration requires knowledge and skills that may not yet be formed in students, which increases the load that does not correspond to the level of education;

- changing the role of the teacher - the transition from instructive and leadership roles to optimizing the educational process;

- in the practice of solving financial problems, group work is not always effective and takes place.

Within the framework of the considered PBL approach, it is advisable to single out the so-called Project Based Learning - the method of projects, although in fact the nature of this method is not much different from the problem-oriented PBL approach [11, 12]. The activity of students is joint and independent when working on financial projects and involves the same positive and negative features as PBL activity. The main difference is that when working on a project, as a rule, there is no time limit for the lesson and extracurricular independent and joint work of students is assumed, the result of which, as a rule, is considered an individual or group presentation on the project.

Learning based on the use of information resources or RBL (Resource Based Learning). Learning with the help of a personal computer, which intersects with all those considered earlier, since an independent search for information to solve problems, work on projects, and conduct an independent research are associated with the use of information resources, computer and information technologies.

At the time of the development of digital technologies, only computers can provide access to information, electronic databases for students and teachers, opening up opportunities for the preparation of written works of appropriate quality, including using modern graphic and design features. Computer technologies are also useful directly for training in the disciplines of the financial cycle. These are various training computer programs (for practicing the skills of a financial analyst and accountant, accounting for personal finances); training programs and materials offering assimilation of information, business games, solving financial problems, online lectures, testing [13, 14, 15].

In the context of a pandemic, special attention deserves the popular online education today, in particular, financial literacy. The Internet is full of various advertisements that offer effective, interesting and in the shortest possible time to teach everyone the basics of financial literacy remotely, via Skype, etc. What are the main advantages of this teaching method over traditional classroom teaching? Undoubtedly, the most attractive moment is the flexibility in the organization of the learning process itself - the students themselves decide when, where and how long their lesson will take, which for many students is a 
decisive factor when choosing online education. The advantage of the online format for many students is the asynchrony of training, in which the student has the opportunity to prepare his report, message, present them repeatedly returning to the messages of other course participants, which creates more comfortable psychological learning conditions. Thus, inactive and less prepared students, who, as a rule, are indecisive in their answers in a traditional class in the classroom, take part in the online discussion on an equal basis with everyone. Although, in the context of a pandemic, today such Internet technologies are widely used in the educational process, which make it possible to organize online conferences, discussions and other training events for all training participants in real time.

All the presented advantages of online learning suggest that it is necessary to take into account that the main responsibility for learning outcomes lies with the learner himself, who actually determines for himself the degree of participation in the educational process $[16,17,18]$. This characteristic of online learning requires the student to have an internal culture, knowledge and observance of the laws of human communication, moral rules and norms, certain skills in time management, and skills in working with information. Certain difficulties for the student can be presented by such features of online learning as the lack of an atmosphere of cooperation and mutual assistance, which is typical, as a rule, for traditional group lessons in the classroom, as well as the remoteness of feedback from the teacher in terms of time. Of course, commenting on the student's answer, the teacher gives comments and recommendations, but they are not always timely. However, despite certain difficulties, online education in the modern conditions of the pandemic is yielding results, and in financial education, in particular.

Despite the fact that the distance format is gradually being introduced into the training system, the authors note that at present there are quite a few sites that allow implementing the educational process without losing quality. The high level of training of modern youth in the field of digital technologies, awareness and awareness in this area allows you to use the most effective and affordable ways to implement the educational process in a distance format. Currently, video conferencing systems such as: TrueConf, Skype, VideoMost, Cisco WebEx, Google Hangouts expand the possibilities for the implementation of any educational projects $[19,20,21]$.

Effective systems for the closest contact between the teacher and the student can be considered sites for online conferences (Zoom, Freeconferencecall, etc.), the capabilities of which are not limited to the implementation of the educational process in a lecture format, but also allow the use of presentation material, conduct surveys, and demonstrate visually the implementation of a number assignments and other types of activities during classes.

The high degree of involvement of modern youth in the information environment, the availability of a sufficient amount of knowledge to use the virtual educational environment expands the possibilities for adapting the material, the form of the lesson for a specific audience of students.

The information environment offers platforms for video conferencing that are different in their functionality and capabilities. TrueConf, MyOwnConference, VideoMost, ClickMeeting, CiscoWebEx, GoTo Meeting are aimed at solving problems of various scales, using visual, audio and video material. The optimal site can be chosen not only based on the level of knowledge of the audience, but also on the technical capabilities that they have to participate in the educational process.

All educational technologies reviewed are effective and relevant. They got their names from the authors who developed them and presented them in the scientific and methodological literature. However, this does not mean at all that these methods have not been used in the educational process before. Each teacher understands that you cannot teach anyone anything, you can only learn, and the main task of the teacher is to help the student discover new financial and economic knowledge for him. It is this goal that should be 
served by personality-oriented educational technologies aimed at developing self-education skills, the ability to work independently and in a team, acquire knowledge from direct experience, use theoretical knowledge and skills in real life or professional financial situations [22].

The formation of financial literacy among students is one of the key problems that are currently being solved through the higher education system. Raising the level of the financial culture of the younger generation is an urgent task for the country, because knowledge of the fundamental economic foundations, knowledge of the concepts and categories of the financial and economic sphere will allow avoiding many problems in the future. Financial literacy training contributes to the most effective functioning of the domestic economy.

The pandemic, which has made its own adjustments to the organization of the educational process, made it possible to look differently at the organization of education around the world, its operational restructuring while maintaining quality and effectiveness.

Information technologies, which in this case are an integral component, are designed to increase the effectiveness of teaching financial literacy, they contribute to the most optimal communication between the teacher and the student and directly to the students. The use in the educational process of various multimedia and computer tools, educational technologies, including information technologies, increase the degree of clarity of the educational material and give the training a practical character. The use of information technology in teaching financial literacy directly contributes to an increase in the degree of interest of students, their motivation for cognitive activity and the study of economic sciences.

Modern teaching methods based on a student-centered approach in all the options considered can deservedly take a leading role in the teaching methods of financial disciplines, which in turn, in combination with information support, will allow achieving high learning outcomes.

\section{References}

1. I.S. Vinnikova, E.A. Kuznetsova, S.V. Oleneva, On the issue of educational technologies in the study of financial disciplines on the basis of a personality-oriented approach, Problems of modern pedagogical education, 68-2, 62-65 (2020).

2. V.I. Liseenko, Features of personality-oriented education at the university: forms of implementation, features, problems, Young scientist, 15, 530-536 (2017)

3. A.V. Zelentsova, E.A. Bliskavka, D.N. Demidov, Increasing the financial literacy of the population: international experience and Russian practice, 112 (2012)

4. Yu.A. Antonova We discuss and play: creative tasks for children on financial literacy, 56 (2017).

5. I.S. Vinnikova, E.A. Kuznetsova, Yu.G. Shutova, D.S. Starodubova, Pedagogical features of the formation of financial literacy among students of economic training, Internet magazine "World of Science", 4(6) (2016) http://mirnauki.com/PDF/39PDMN616.pdf

6. A.A. Popkova, O.I. Vaganova, Z.V. Smirnova, E.A. Kuznetsova, I.S. Vinnikova, Economic Socialization in University, In the collection: Lecture Notes in Networks and Systems. Growth Poles of the Global Economy: Emergence, Changes and Future Perspectives. Plekhanov Russian University of Economics, 1049-1056 (2020) DOI: 10.1007/978-3-030-15160-7_105 
7. I.S. Vinnikova, E.A. Kuznetsova, A.K. Zakaria, Organization of independent work of students in economic areas of training in the study of financial mathematics, Problems of modern pedagogical education, 60-1, 61-64 (2018)

8. S.M. Gulyants, The essence of a personality-oriented approach in teaching from the point of view of modern educational concepts, Bulletin of the Chelyabinsk State Pedagogical University, 2, 40-52 (2009)

9. V.V. Dobroselsky, Personality-oriented approach in training future bachelormanagers, Bulletin of the Southern Federal University. Pedagogical sciences, 10, 125 130 (2017)

10. Yu.N. Sklyarova, Modern educational technologies of a personality-oriented approach in education, Actual problems of modern pedagogy: mater. VI int. scientific. Conf., 33$36(2015)$

11. A.T. Anisimova, Educational technologies of teaching a foreign language based on a personality-oriented approach, Scientific Bulletin of YIM, 3, 75-80 (2014)

12. O.F. Turyanskaya Theoretical Foundations of Personally Oriented Approach to Learning, 278 (2015).

13. M. Studneva, S. Grachev, A. Kostalevskaya, Basic principles of a personality-oriented approach to learning, In the collection: Actual questions of psychology and pedagogy in modern conditions, 137-138 (2015)

14. I.S. Yakimanskaya, Personality-oriented education in modern school, 96 (2006)

15. V.V. Korableva, S.I. Artemyeva, Personality-oriented approach in higher education, In the collection: Theoretical and pragmatic aspects of human development in the educational space, 169-172 (2020)

16. V.V. Afanasyev, I.V. Afanasyeva, Combined approach as a methodological basis for managing a personality-oriented learning process, Materials of the All-Russian scientific and practical conference: Diagnostics of the functioning of pedagogical systems of higher education, 154-157 (1998)

17. G.T. Klinkov, M.A. Rodionov, O.E. Kozlova, E.V. Vezetiu, E.V. Vovk, Implementation of discussion technologies in a personality-centered professional education, Amazonia Investiga, 26, 82-87 (2020) DOI: 10.34069 / AI / 2020.26.02.9

18.Z.V. Smirnova, O.I. Vaganova, I.S. Vinnikova, A.V. Lapshova, O.V. Golubeva, Modern multimedia didactic tools of interactive training. In the collection: Lecture Notes in Networks and Systems. Growth Poles of the Global Economy: Emergence, Changes and Future Perspectives. Plekhanov Russian University of Economics, 485491 (2020) DOI: 10.1007 / 978-3-030-15160-7_49.

19. Kh.Kh. Shamanova, E.M. Vishnevskaya, Interactive technologies as a means of implementing a personality-oriented approach in teaching, Problems of modern pedagogical education, 62-4, 244-246 (2019)

20.I.V. Abramova Personally-oriented teaching of students as a condition for the formation of their professional competence, Problems of modern teacher education, 592, 7-10 (2018)

21. M.P. Prokhorova, O.I. Vaganova, Design and implementation of an educational event in the training of future managers, Vestnik of Minin University, 7(1):4 (2019)

22. V.V. Dobroselsky, Personality-oriented approach in training future bachelormanagers, Bulletin of the Southern Federal University. Pedagogical sciences, 10, 125 130 (2017) 